\title{
Infant and young child feeding practices and its determinants in an urbanized village of Delhi
}

Introduction: Optimal infant and young child feeding (IYCF) practices are fundamental for the survival, health, growth, and development of children. It is important to study factors that determine these practices in a community. The present study is designed to assess the prevalence of optimal IYCF practices and its determinants in an urbanized village of Delhi. Materials and Methods: Mothers of children 0-23 months of age were interviewed using a structured and semi open-ended questionnaire to record information on IYCF practices. Results: A total of 194 children were included in the study. Breastfeeding (BF) was initiated within $1 \mathrm{~h}$ of birth in $49.5 \%$ of children. Early initiation of BF was significantly higher in children born in government institutions, normal births and in families with higher income. Prelacteal feeds were given by $47.4 \%$ of mothers, children born at home and private institution and caesarean births received prelacteal feeds more often. Colostrum was given by $79.4 \%$ of the mothers. Children born in the government institution were more likely to receive colostrum $(P<0.05)$. The prevalence of exclusive BF (EBF) for 6 months or more was $56.5 \%$. It was higher in children of first birth order and institutional births $(P<$ 0.05). Complementary feeding was started at 6 months in $54.6 \%$ of these children. Children of mothers with higher education and boys were more likely to be started on timely complementary feeding than girls. Conclusions: The IYCF practices in the area were not satisfactory, although better than the national average. Early initiation and EBF for 6 months were higher in children born in government institutions. Thus, awareness about IYCF practices has to be increased among the health personnel in the public and private sectors and mothers.

Key words: Complementary feeding, exclusive breastfeeding, infant and young child

Anita Gupta, Pragti Chhabra

Department of Community Medicine, University College of Medical Sciences, New Delhi, India

Address for the Correspondence:

Dr. Pragti Chhabra, Department of Community Medicine, University College of Medical Sciences, New Delhi - 110 095, India. E-mail: pragschhabra@ yahoo.co.in

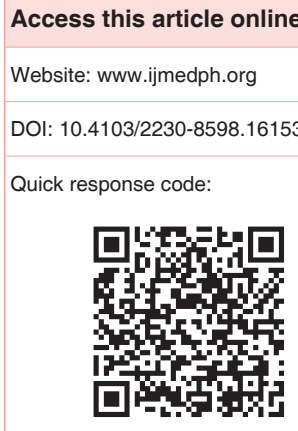

feeding, initiation of breastfeeding

\section{INTRODUCTION}

India has shown a decline in the under-five child mortality indicators, but the rates are not sufficient to achieve the Millennium Development Goal 4 by 2015..$^{[1,2]}$ India is home to almost one-third of world's underweight children with an estimated prevalence of underweight, stunting, and wasting being $40 \%, 45 \%$, and 23\% respectively among under-three children. ${ }^{[3]}$ Malnutrition has been estimated to be an underlying cause of up to $50-60 \%$ of under-five deaths. Over two-thirds of these deaths are associated with inappropriate feeding practices. Evidence has proven that optimal breastfeeding (BF) and complementary feeding are among the most cost-effective child survival interventions that could prevent $13 \%$ and $6 \%$, respectively, of under-five child deaths. ${ }^{[4-6]}$

To revitalize world attention to the impact that feeding practices have on the nutritional status, growth, development, health, and survival of infants and young children, the global strategy for infant and young child feeding (IYCF) was adopted by the World Health Organization and UNICEF in 2002. ${ }^{[7]}$ The national guidelines on IYCF were developed in 2006 to give further impetus to optimal IYCF practices. ${ }^{[8]}$ Data from the national family health survey 3 (NFHS-3), district-level household and facility survey (DLHS) and studies on infant feeding practices show that the rates of these continue to remain low. ${ }^{[3,9-11]}$ Infant and child feeding in a community is influenced by various factors at the individual, family, and community level. It is important to study these factors so as to build suitable strategies to improve these practices. The present study was conducted to assess the prevalence of IYCF practices in an urbanized village of East Delhi and the determinants of these practices. 


\section{MATERIALS AND METHODS}

The present study was conducted in an urbanized village of East Delhi. As per census 2001, villages having a population of 4000 or more, a population density of $400 / \mathrm{km}^{2}$ or more and having at least $75 \%$ male working population engaged in non-agricultural activity are classified as urban.

The study was conducted among mothers of children $<24$ months of age, who were resident in the area for $>6$ months. Assuming a prevalence of exclusive $\mathrm{BF}(\mathrm{EBF})$ rate of $46 \%$ as per DLHS and absolute error of $6 \%$ at $90 \%$ confidence level, a sample size of 187 was calculated using Epi Info software 7, Centers for Disease Control, Atlanta, USA. There are six Anganwadi centers in the area, approximately 60-70 children of age 0-23 months are listed in the survey register of each Anganwadi center. By systematic random sampling, every second child was enrolled, and the mother was contacted at home and consent was obtained. Those available and willing were interviewed using a pretested, structured, and semi-open-ended questionnaire to record information about sociodemographic profile, details of ante natal care, place of birth, type of delivery; and IYCF practices namely initiation of $\mathrm{BF}, \mathrm{EBF}$, prelacteal feeds, feeding of colostrum, and complementary feeding. Age of the child was calculated in completed months on the date of interview. EBF was defined as an infant receives only breast milk or expressed breast milk from his or her mother or a wet nurse, and no other liquids or solids, not even water, with the exception of oral rehydration solution, drops or syrups consisting of vitamins, minerals supplements or medicines prescribed by a physician.

The data were analyzed using Statistical Package for Social Sciences (SPSS, Chicago, IL, USA, Version 16) for Windows software. The prevalence of the IYCF practices was computed, and their association with variables was assessed using Chi-square test.

\section{RESULTS}

Table 1 shows the sociodemographic characteristics of 194 children $<24$ months included in the study. Almost two-third (67\%) of the children were $<1$-year while $33 \%$ were in the $12-23$ months age group. Boys constituted $54.1 \%$ and girls $45.9 \%$ of the children. About $37 \%$ of mothers and $13 \%$ of fathers had received no formal education; majority belonged to nuclear families (78\%). Most (88.7\%) of the mothers had registered during pregnancy, $55.4 \%$ during the first trimester and $33.3 \%$ second trimester, while $31.3 \%$ had three or less and $52.4 \%$, had $>3$ antenatal care check-ups and $85.1 \%$ had a normal vaginal delivery. About $57 \%$ of the children were delivered at a government health institution, $20 \%$ in the private institution and $23 \%$ were delivered at home. As shown in Table $2 \mathrm{BF}$ was initiated within $1 \mathrm{~h}$ of birth in $95(49.5 \%)$ children. Mothers with family income of $>$ Rs. 5000 were more likely to initiate BF early as compared to those with lesser income $(P<0.01)$. The proportion of children who received BF within $1 \mathrm{~h}$ of birth was higher in those born in government institutions as compared to those born at home or private institution $(P<0.01)$. Initiation of $\mathrm{BF}$ was delayed for $>24 \mathrm{~h}$ in $58.6 \%$ of children born by caesarean section as compared to $16.9 \%$ in

\begin{tabular}{|c|c|}
\hline Factor & $n(\%)$ \\
\hline \multicolumn{2}{|l|}{ Age group of children } \\
\hline 0-6 months & $56(28.9)$ \\
\hline 7-12 months & $74(38.1)$ \\
\hline $13-24$ months & $64(33.0)$ \\
\hline \multicolumn{2}{|l|}{ Gender } \\
\hline Boys & $105(54.1)$ \\
\hline Girls & $89(45.9)$ \\
\hline \multicolumn{2}{|l|}{ Type of family } \\
\hline Nuclear & $151(77.8)$ \\
\hline Joint & $43(22.2)$ \\
\hline \multicolumn{2}{|l|}{ Education of mother } \\
\hline Illiterate & $67(37.5)$ \\
\hline $1-10$ years & $88(45.4)$ \\
\hline More than 10 years & $39(20.0)$ \\
\hline \multicolumn{2}{|l|}{ Education of father } \\
\hline Illiterate & $25(12.9)$ \\
\hline $1-10$ years & $102(52.3)$ \\
\hline More than 10 years & $67(34.5)$ \\
\hline \multicolumn{2}{|l|}{ Occupation of father } \\
\hline Unemployed & $4(2.1)$ \\
\hline Unskilled or skilled & $124(63.9)$ \\
\hline Clerk or shop keeper & $66(34)$ \\
\hline \multicolumn{2}{|l|}{ Place of delivery } \\
\hline Government institution & $110(56.7)$ \\
\hline Private institution & $38(19.6)$ \\
\hline Home & $46(23.7)$ \\
\hline Total & 194 \\
\hline
\end{tabular}

Figures in parentheses are percentage

\begin{tabular}{|c|c|c|c|c|}
\hline Factor & $<1 \mathrm{~h}$ & $1-24 \mathrm{~h}$ & $\begin{array}{c}\text { More } \\
\text { than } 24 \mathrm{~h}\end{array}$ & $P$ \\
\hline \multicolumn{5}{|l|}{ Sex of child } \\
\hline Male $(n=105)$ & $58(55.2)$ & $27(25.7)$ & $20(19.0)$ & \multirow[t]{2}{*}{0.179} \\
\hline Female $(n=89)$ & $38(42.7)$ & $26(29.2)$ & $25(28.1)$ & \\
\hline \multicolumn{5}{|l|}{ Birth order of child } \\
\hline$\leq 2(n=143)$ & $72(50.3)$ & $35(24.5)$ & $36(25.2)$ & \multirow[t]{2}{*}{0.286} \\
\hline$>2(n=51)$ & $25(48.1)$ & $18(34.6)$ & $9(17.3)$ & \\
\hline \multicolumn{5}{|l|}{ Family income } \\
\hline$\leq 5000(n=29)$ & $8(27.6)$ & $14(48.3)$ & $7(24.1)$ & \multirow[t]{3}{*}{$0.021^{*}$} \\
\hline $5001-10,000(n=125)$ & $70(56.0)$ & $30(24.0)$ & $25(20.0)$ & \\
\hline$>10,000(n=40)$ & $18(45.0)$ & $9(22.5)$ & $13(32.5)$ & \\
\hline \multicolumn{5}{|l|}{ Place of birth } \\
\hline $\begin{array}{l}\text { Government institution } \\
(n=110)\end{array}$ & $65(58.2)$ & $28(25.5)$ & $18(16.4)$ & \multirow[t]{3}{*}{$0.009^{*}$} \\
\hline Private institution $(n=38)$ & $10(26.3)$ & $14(36.8)$ & $14(36.8)$ & \\
\hline Home $(n=46)$ & $22(47.8)$ & $11(23.9)$ & $13(28.2)$ & \\
\hline \multicolumn{5}{|l|}{ Type of delivery } \\
\hline Normal $(n=165)$ & $8652.4)$ & $51(30.7)$ & $28(16.9)$ & \multirow[t]{3}{*}{$<0.001^{*}$} \\
\hline Caesarean section $(n=29)$ & $10(34.5)$ & $2(6.9)$ & $17(58.6)$ & \\
\hline Total $(n=194)$ & $96(49.5)$ & $53(27.3)$ & $45(23.2)$ & \\
\hline
\end{tabular}

Figures in parentheses are percentage, $* P<0.05$, significant

those with normal delivery. Table 3 shows factors associated with the practice of giving prelacteal feeds and colostrum feeding. Prelacteal 
feeds were given by $47.4 \%$ of mothers; children were born at home and private institutions and caesarean births received prelacteal feeds more often as compared to those born in government institutions and those with normal birth, respectively. Colostrum was given by $79.4 \%$ of the mothers. Children born in the government institution were more likely to receive colostrum $(P<0.05)$.

Exclusive breastfeeding for 6 months or more was studied in 138 children $>6$ months of age [Table 4]. Among these, 56.2\% were EBF for at least 6 months. Prevalence of EBF was significantly more in children of birth order $<2$, those born in government institutions and those with a normal birth $(P<0.05)$.

\begin{tabular}{|c|c|c|c|c|}
\hline Factor & $\begin{array}{c}\text { Prelacteal } \\
\text { feeds given }\end{array}$ & $P$ & $\begin{array}{l}\text { Colostrum } \\
\text { given }\end{array}$ & $P$ \\
\hline \multicolumn{5}{|l|}{ Sex of child } \\
\hline Male $(n=105)$ & $45(42.9)$ & 0.195 & 91 (86.7) & 0.106 \\
\hline Female $(n=89)$ & $47(52.8)$ & & $66(74.2)$ & \\
\hline \multicolumn{5}{|l|}{ Birth order } \\
\hline$\leq 2(n=143)$ & $67(46.9)$ & 1.00 & $115(80.4)$ & 1.00 \\
\hline$>2(n=51)$ & $25(48.1)$ & & $42(80.8)$ & \\
\hline \multicolumn{5}{|l|}{ Place of birth } \\
\hline $\begin{array}{l}\text { Government } \\
\text { institution }(n=110)\end{array}$ & $43(38.7)$ & $0.018^{*}$ & $102(91.9)$ & $<0.001^{*}$ \\
\hline $\begin{array}{l}\text { Private institution } \\
(n=38)\end{array}$ & $24(63.2)$ & & $26(68.4)$ & \\
\hline Home $(n=46)$ & $25(54.3)$ & & $29(63.0)$ & \\
\hline \multicolumn{5}{|l|}{ Type of delivery } \\
\hline Normal $(n=165)$ & $72(43.4)$ & $0.015^{*}$ & $135(81.3)$ & 0.458 \\
\hline $\begin{array}{l}\text { Caesarean } \\
\text { section }(n=29)\end{array}$ & $20(69.0)$ & & $22(75.9)$ & \\
\hline Total $(n=194)$ & $92(47.4)$ & & $154(79.4)$ & \\
\hline
\end{tabular}

Complementary feeding was started at 6 months in $54.6 \%$ before in $20.3 \%$, and after 6 months in $24.8 \%$ of the children. Boys were more likely to be started on complementary feeding at 6 months as compared with girls. Education of mother was significantly associated with timely complementary feeding at 6 months.

\section{DISCUSSION}

The present study was conducted in an urbanized village of Delhi to study the infant and young child practices. Initiation of BF was done within $1 \mathrm{~h}$ in $49.5 \%$ of the children. This is comparable to the figure of $41 \%$ for India reported in World Breastfeeding Trends Initiative, $44 \%$ for Delhi reported in Coverage Evaluation Survey (CES) 2009 by UNICEF and DLHS-3 (2007-2008). ${ }^{[9,12,13]}$ However, it is significantly higher than a study conducted in the 90's in an urban resettlement colony of Delhi where only $10 \%$ of mothers reported giving the first $\mathrm{BF}$ within $1 \mathrm{~h}$ of birth. ${ }^{[14]}$ It is higher than the figure of $24.5 \%$ reported in NFHS-3 and other studies in the past. ${ }^{[3,10,11]}$ Recent studies from rural Bengal and urban slums of Lucknow have reported a lower figure than the present study. ${ }^{[15,16]}$ Early initiation was more likely in children born in the government institution as compared to those born at home or a private facility. The NFHS-3 data has also shown the prevalence of initiation of BF to be $34 \%$ among children born in the health facility as compared to $17 \%$ among those born at home. ${ }^{[3]}$ A study in slums of Chandigarh has similarly reported home delivery as a significant factor for delayed initiation. ${ }^{[17]}$ However, a study from Ethiopia has reported that women delivering at home were less likely to delay initiation of $\mathrm{BF}{ }^{[18]}$ Children born by caesarean section were more likely to have delayed initiation of BF. Delivery by Caesarean section has consistently been shown to be a negative factor for early initiation of BF. ${ }^{[17,19,20]}$ Efforts should be made for promotion of early initiation of BF even after caesarean section.

\begin{tabular}{|c|c|c|c|c|}
\hline Factor & $\begin{array}{l}\text { EBF for } \geq 6 \text { months } \\
\text { Number (\%) }\end{array}$ & $P$ & $\begin{array}{l}\text { Complementary feeding at } \\
6 \text { months Number }(\%)\end{array}$ & $P$ \\
\hline \multicolumn{5}{|l|}{ Sex of child } \\
\hline Male $(n=77)$ & $47(61.8)$ & 0.255 & $49(63.6)$ & $0.035^{\star}$ \\
\hline Female $(n=61)$ & $31(50.8)$ & & $26(42.6)$ & \\
\hline \multicolumn{5}{|l|}{ Birth order of child } \\
\hline$\leq 2(n=101)$ & $63(62.4)$ & $0.032^{*}$ & $57(56.4)$ & 0.240 \\
\hline More than $2(n=37)$ & $15(40.5)$ & & $18(48.6)$ & \\
\hline \multicolumn{5}{|l|}{ Mother's education } \\
\hline Illiterate $(n=45)$ & $22(48.9)$ & 0.122 & $18(40.0)$ & $0.023^{*}$ \\
\hline $1-10$ years $(n=64)$ & $34(53.1)$ & & $36(56.3)$ & \\
\hline$>10$ years $(n=29)$ & $21(72.4)$ & & $21(72.4)$ & \\
\hline \multicolumn{5}{|l|}{ Place of birth } \\
\hline Government institution $(n=79)$ & $52(65.8)$ & $0.039^{*}$ & $43(54.4)$ & 0.446 \\
\hline Private institution ( $n=27)$ & $12(44.4)$ & & $16(59.3)$ & \\
\hline Home $(n=32)$ & $14(43.8)$ & & $16(50)$ & \\
\hline \multicolumn{5}{|l|}{ Type of delivery } \\
\hline Normal $(n=101)$ & $65(57.0)$ & 0.824 & $60(52.6)$ & 0.476 \\
\hline Caesarean section $(n=24)$ & $13(54.2)$ & & $15(62.5)$ & \\
\hline Total $(n=138)$ & $78(56.5)$ & & $75(54.3)$ & \\
\hline
\end{tabular}

$* P<0.05$, significant, EBF $=$ Exclusive breastfeeding 
Prelacteal feeds were given by $47.4 \%$ of the mothers, which is comparable to $45.5 \%$ observed in NFHS-3 for Delhi but lower than an earlier study from Delhi and that reported from previous other studies. ${ }^{[3,10,11,14]}$ The decrease may be attributed to the increase in proportion of institutional deliveries and increased awareness. The practice of feeding colostrum was observed in $80 \%$ of the children and is comparable to that observed in the slums of Chandigarh and CES 2009. ${ }^{[13,17]}$ The probability of early initiation and feeding of colostrum has been observed to be higher with institutional births.

Exclusive breastfeeding for 5 months was reported by $56 \%$ of the mothers, which is lower than the goal of increasing EBF rates at annual rate of $9.6 \%$ from the baseline of $36 \%$ observed in the CES 2009 as laid out in the $12^{\text {th }} 5$ years plan. ${ }^{[13,21]}$ The rate is though higher than that observed in NFHS-3, previous studies and that reported in World Breastfeeding Trends Initiative, South Asia Report Card 2012. Our neighboring countries viz., Bangladesh, Nepal and Sri Lanka have higher EBF rates of 64, 70, and 76, respectively. Children with birth order $<2$ and those born in institutions were more likely to be exclusively breastfed. This is similar to observation in the earlier study from Delhi; however a study based on NFHS-2 data has shown delivery in a health facility to be a risk factor for not exclusively BF while another has reported no consistent association. ${ }^{[20,22]}$ The type of facility has not been specified in the studies. The EBF rates were similar for births at home and private facility in the present study, indirectly highlighting the role of staff of the government facilities in promotion of BF. The private facilities need to make their institutions BF friendly by adopting the baby friendly institution initiative.

Almost $54 \%$ of children were started on complementary feeding at 6 months of age. This is similar to $55 \%$ reported in NFHS-3 and studies from other parts of India; but lower than $63.2 \%$ in DLHS Delhi and 62\% in CES 2009 ${ }^{[3,9,10,13,23]}$ A significantly higher number of boys received complementary feeding as compared to girls. This could be due to the preferential treatment to boys in our society. In a study on comparison of IYCF indicators of the South East Asian region, the timely Complementary rates were highest for Sri Lanka and lowest for India. Higher maternal education was associated with timely complementary feeding in Nepal, similar to the present study. However, no factor was observed to be consistently associated with timely complementary feeding rates across the countries. ${ }^{[2]}$

Thus, the present study shows that the rates of timely initiation of BF, EBF, and complementary feeding have improved but have not reached the desired targets. The BF practices were better in children born in government institutions highlighting the role of health facilities in improving IYCF practices. Awareness about IYCF practices has to be increased among the health personnel in public and private sectors and mothers.

\section{REFERENCES}

1. National Health Profile 2012. Central Bureau of Health Intelligence, Directorate General Health Services, Ministry of Health and Family Welfare, Government of India; 2012.
2. Bhutta ZA, Chopra M, Axelson H, Berman P, Boerma T, Bryce J, et al. Countdown to 2015 decade report (2000-10): taking stock of maternal, Newborn, and child survival. Lancet 2010;375:2032-44.

3. International Institute for Population Sciences (IIPS), India and Macro International. National Family Health Survey (NFHS-3), 2005-6: India. Vol. I. Mumbai: IIPS; 2007.

4. Black RE, Allen LH, Bhutta ZA, Caulfield LE, de Onis M, Ezzati M, et al. Maternal and child undernutrition: Global and regional exposures and health consequences. Lancet 2008;371:243-60.

5. Jones G, Steketee RW, Black RE, Bhutta ZA, Morris SS, Bellagio Child Survival Study Group. How many child deaths can we prevent this year? Lancet 2003;362:65-71.

6. Bryce J, Coitinho D, Darnton-Hill I, Pelletier D, Pinstrup-Andersen P, Maternal and Child Undernutrition Study Group. Maternal and child undernutrition: Effective action at national level. Lancet 2008;371:510-26.

7. World Health Organization. Global Strategy for Infant and Young Child Feeding. Geneva: World Health Organization; 2003.

8. National Guidelines on Infant and Young Child Feeding. New Delhi: Ministry of Women and Child Development (Food and Nutrition Board) and Ministry of Human Resource Development, Government of India; 2006.

9. International Institute for Population Sciences (IIPS). District Level Household and Facility Survey 2007-08 India. Mumbai: IIPS; 2008.

10. Bavdekar SB, Bavdekar MS, Kasla RR, Raghunandana KJ, Joshi SY, Hathi GS. Infant feeding practices in Bombay slums. Indian Pediatr 1994;31:1083-7.

11. Srivastava SP, Sharma VK, Kumar V. Breast feeding pattern in neonates. Indian Pediatr 1994;31:1079-82.

12. World Breastfeeding Trends Initiative South Asia Report Card 2012. International Baby Food Action Network (IBFAN), Asia and Breastfeeding Promotion Network of India (BPNI) Delhi; 2013.

13. United Nations Children Fund (UNICEF) Coverage Evaluation Survey 2009. UNICEF; 2010.

14. Chhabra P, Grover VL, Aggarwal OP, Dubey KK. Breast feeding patterns in an urban resettlement colony of Delhi. Indian J Pediatr 1998;65:867-72.

15. Gupta P, Srivastava V, Kumar V, Jain S, Masood J, Ahmad N, et al. Newborn Care Practices in Urban Slums of Lucknow City, UP. Indian J Community Med 2010;35:82-5.

16. Das N, Chattopadhyay D, Chakraborty S, Dasgupta A. Infant and young child feeding perceptions and practices among mothers in a rural area of West Bengal, India. Ann Med Health Sci Res 2013;3:370-5.

17. Kumar D, Agarwal N, Swami HM. Socio-demographic correlates of breastfeeding in urban slums of Chandigarh. Indian J Med Sci 2006;60:461-6.

18. Horii N, Guyon AB, Quinn VJ. Determinants of delayed initiation of breastfeeding in rural Ethiopia: Programmatic implications. Food Nutr Bull 2011;32:94-102.

19. Raghavan V, Bharti B, Kumar P, Mukhopadhyay K, Dhaliwal L. First hour initiation of breastfeeding and exclusive breastfeeding at six weeks: Prevalence and predictors in a tertiary care setting. Indian $\mathrm{J}$ Pediatr 2014;81:743-50.

20. Patel A, Badhoniya N, Khadse S, Senarath U, Agho KE, Dibley MJ, et al. Infant and young child feeding indicators and determinants of poor feeding practices in India: Secondary data analysis of National Family Health Survey 2005-06. Food Nutr Bull 2010;31:314-33.

21. Ministry of Health and Family Welfare. A Strategic Approach to Reproductive, Maternal, Newborn, Child and Adolescent Health (RMNCH + A) in India. New Delhi: Government of India; 2013. p. 10-1.

22. Dibley MJ, Roy SK, Senarath U, Patel A, Tiwari K, Agho KE, et al. Acrosscountry comparisons of selected infant and young child feeding indicators and associated factors in four South Asian countries. Food Nutr Bull 2010;31:366-75.

23. Meshram II, Laxmaiah A, Venkaiah K, Brahmam GN. Impact of feeding and breastfeeding practices on the nutritional status of infants in a district of Andhra Pradesh, India. Natl Med J India 2012;25:201-6.

How to cite this article: Gupta A, Chhabra P. Infant and young child feeding practices and its determinants in an urbanized village of Delhi. Int J Med Public Health 2015;5:228-31.

Source of Support: Nil, Conflicts of Interest: None declared. 